\title{
The Challenges in Enrolment and Retention of African Women in Clinical Trials: A Pilot Study in Nigeria
}

\author{
Chukwuneke $\mathrm{FN}^{1 *}$, Ekwueme $\mathrm{OC}^{2}$, Ezeonu $\mathrm{PO}^{3}$, Onyire $\mathrm{BN}^{4}$ and Ifebunandu $\mathrm{N}^{5}$
}

${ }^{1}$ Senior Lecturer/Consultant, Department of Oral and Maxillofacial Surgery, College of Medicine, University of Nigeria Teaching Hospital, Enugu, Nigeria

${ }^{2}$ Senior Lecturer/Consultant, Department of Community Medicine University of Nigeria Teaching Hospital, Enugu, Nigeria

${ }^{3}$ Consultant, Department of Obstetrics \& Gynaecology, Federal Teaching Hospital, Abakiliki Ebonyi State, Nigeria

${ }^{4}$ Consultant, Department of Paediatrics, Federal Teaching Hospital, Abakiliki Ebonyi State, Nigeria

${ }^{5}$ Consultant, Department of Internal Medicine, Federal Medical Centre, Abakiliki Ebonyi State, Nigeria

\begin{abstract}
Background: The difficulties of recruiting and retaining African women in biomedical research cannot be overemphasized. Despite the epidemiologic and gender distribution of the burden of diseases in Africa, women scarcely participate in biomedical research especially in clinical trials. This paper critically examines the challenges involved in recruiting and retaining African women in clinical trials using a pilot study in Nigeria.

Methods: We carried out a pilot study through self-administered semi-structured questionnaire on knowledge, constraints and willingness by women to participate in clinical trials. Females attending outpatient obstetrics and gynecology clinics in Nigeria were the participants. The data collected was converted to numerical values for generation of statistic analysis.

Results: Out of the 200 questionnaires distributed, 172 were returned anonymously representing $86 \%$ response rate, which were used in the data analysis. Eighty-two (47.7\%) were willing to participate depending on the type of trials while $60(35 \%)$ were concerned about monetary compensation. Most of the respondents $(p<0.05)$ were of the opinion that their husbands and families must be in support before they could participate.

Discussion and Conclusion: This study has shown that knowledge and education play important role in motivating women to participate in clinical trials in Africa while family attachments and cultural barrier is an impediment to their participation. This calls for an awareness campaign to emphasize not only the necessity for women participation in clinical trial but also the establishment of adequate protective and educative measures for those willing to participate in a male dominated society like Nigeria.
\end{abstract}

Keywords: Clinical trials; African women; Participation; Challenges; Nigeria

\section{Introduction}

The difficulties of recruiting and retaining women in clinical trials as experienced in Africa cannot be underestimated. Despite the epidemiologic realities of the trends and burden of diseases in Africa, women have had minimal participation in clinical trials [1]. Gender concept and perception of "woman" in Africa and the paternalistic stance of men [2] had often led to a default position of excluding women from biomedical research by some researchers who are not exempted from this stereotype gender position in Africa as most of their study designs and methodologies often exclude women. The various and intertwined aspects of gender roles and power dynamics including women's fulfillment of roles as mothers and caregivers are strong impediments to full participation in clinical trials [3]. In Africa, while men can make decisions freely, women may lack the decisionmaking freedom to participate in a trial, especially a trial that addresses sensitive issues such as sexual behavior. Also they may be burdened with childcare, domestic work and limited mobility which often affects their full participation. Women need to participate in clinical trials because of their different biological and physiological make-up, which require proper information about the effects of drugs on their bodies [4]. Gender inequity in clinical trials has resulted in research outcomes too small to yield meaningful information about treatment and burden of disease on different groups [5]. For example, evidence has shown that researchers' opinions and findings differed in characterizing the prevalence of some diseases such as AIDS, heart disease and lung cancer among men and women [6]. Therefore, a variety of harm may ensue from failure to include and retain adequate numbers of women in clinical trials such as exposure to ineffective treatment, occurrence of unexpected side-effects and delayed diagnosis and early treatment of disease. There are also other reasons African women should be recruited in clinical trials, and they include; understanding the extent of the health problem, finding out which groups within the population are at highest and lowest risk, and characterizing the clinical response of the trial in women in comparison to that of men. This in turn will assist health policy makers to evaluate the allocation of resources for more research, prevention, treatment, and support services in an environment like Nigeria that carries the burden of many diseases. The purpose of this paper was to critically examine and identify the challenges involved in recruiting and retaining African women in clinical trials using a pilot study in Nigeria.

\section{Methods}

In this pilot study, 200 semi-structured questionnaires on

${ }^{*}$ Corresponding author: Dr. Chukwuneke FN, Senior Lecturer/Consultant Department of Oral and Maxillofacial Surgery, College of Medicine, University of Nigeria Teaching Hospital, Enugu, Nigeria, Tel: +2347064531609; E-mail: ichiefn2002@yahoo.com

Received December 06, 2011; Accepted April 25, 2012; Published April 30, 2012

Citation: Chukwuneke FN, Ekwueme OC, Ezeonu PO, Onyire BN, Ifebunandu N (2012) The Challenges in Enrolment and Retention of African Women in Clinical Trials: A Pilot Study in Nigeria. J Clinic Res Bioeth 3:133. doi:10.4172/21559627.1000133

Copyright: (C) 2012 Chukwuneke FN, et al. This is an open-access article distributed under the terms of the Creative Commons Attribution License, which permits unrestricted use, distribution, and reproduction in any medium, provided the original author and source are credited. 
Citation: Chukwuneke FN, Ekwueme OC, Ezeonu PO, Onyire BN, Ifebunandu N (2012) The Challenges in Enrolment and Retention of African Women in Clinical Trials: A Pilot Study in Nigeria. J Clinic Res Bioeth 3:133. doi:10.4172/2155-9627.1000133

Page 2 of 3

knowledge, constraints and willingness to participate in clinical trials were randomly distributed among females attending out-patient obstetrics and gynecology clinics in Nigeria. The targeted populations were Nigerian women living in both urban and rural areas. The focus was on identifying the challenges involved in recruiting and retaining women in clinical trials. The eleven-part questionnaires that we distributed were the same and were returned anonymously. Before proceeding with the questionnaire, we obtained the socio-demographic data of all the research participants. Question 1 was designed to establish the level of knowledge about clinical trials research amongst the respondents. Invitations as well as acceptance to participate in clinical trials were addressed in question 3 and 4 while question 5 was specific on the type of clinical trial for those who accepted the invitation to participate. Reasons for refusal to participate in the clinical trials on invitation were addressed in question 6 which include: religious beliefs, cultural barriers, family response, type of clinical trials, monetary compensation, time pressure and environmental factor. Each respondent therefore marked the corresponding reason according to her personal experience and feeling regarding her refusal to participate in the clinical trials. For those who have never been invited to participate in clinical trials, question 7 was specific on their willingness to participate if invited. The general view on what respondents may consider as motivating factor to ensure their full participation in clinical trials was addressed in question 9 while question 10 was designed to find out the type of clinical trials they consider inappropriate for women participation. In general term, question 11 was designed to find out what the women consider as impediments and challenges to their enrollment and retention in clinical trials. The collected data were entered into a computer with password protection that was only accessible to the principal investigator and thereafter, converted to relative values. These values were in turn double-entered using Micro-soft Excel package and exported to statistic software (STATA) for analysis. Chi-square test of association between respondents' willingness and constraints to participate in clinical trials was carried out. The differences were considered significant at the $\mathrm{p}<0.05$ level. Possible associations between the general views of the respondents and the challenges to fully participate in clinical trials were also determined.

\section{Results}

Out of the 200 questionnaires distributed, 172 were returned anonymously representing $86 \%$ response rate, which were used in the data analysis. The age range of the respondents falls within 15-54 years with mean age of 24 (+ standard deviation 6.2). Of the 172 respondents, 49 (28.5\%) were not married. One hundred and thirty-two $(76.8 \%)$ did not reach tertiary educational level. Among the 172 respondents, 109 (63\%) do not understand what clinical trials was all about, out of which 79 (72\%) were below tertiary educational level. Forty-eight $(27.8 \%)$ respondents agreed they have been invited in the past to participate in clinical trial. Of these 48 respondents, only three (3.4\%) accepted and fully participated while the rest declined. The commonest reasons for refusal were attributed to time pressure and domestic maters (75.8\%) followed by the type of clinical trials $(72.7 \%)$ as shown in Table 1. Overall, out of the 172 respondents, 82 (47.7\%) expressed their willingness to participate but are constrained by other factors such as the type of trials for the fear of adverse effect and religious beliefs. Sixty (35\%) were concerned about monetary compensation. Most of the respondents $139(80.8 \%)$ were of the opinion that their husbands and families must give consent before they could participate while the remaining 33 (19.2\%) did not require their families consent before they can participate. Of these 33 respondents 29 (87.9\%) were unmarried, an indication that unmarried people may have more liberty to make decisions than their married counterpart $\left(\mathrm{p}=0.001^{*}\right)$ as observed (Table 2). In the same vein, attributing family constraints as reasons for unwillingness to participate amongst the 172 respondents was strongly associated with low level of education and awareness $(\mathrm{P}=$ $\left.0.015^{*}\right)$. In general term, what the respondents considered as challenges to women participation and retention in clinical trials (Figure 1) were cultural barrier $(56 \%)$, religious beliefs (32\%) gender inequalities and discriminations (72\%), ignorance and fear of adverse effect (64\%) and

\begin{tabular}{|c|c|c|c|}
\hline $\begin{array}{l}\text { Reasons } \\
\text { P-value }\end{array}$ & Yes & No & $x^{2}$ \\
\hline $\begin{array}{l}\text { Time Pressure } \\
0.001^{\star}\end{array}$ & $36(75.8 \%)$ & $12(24.2 \%)$ & 24.00 \\
\hline $\begin{array}{l}\text { Religious Believe } \\
0.001^{*}\end{array}$ & $13(27.1 \%)$ & $35(72.9 \%)$ & 20.17 \\
\hline $\begin{array}{l}\text { Cultural Barrier } \\
0.221^{*}\end{array}$ & $21(43.8 \%)$ & $27(56.2 \%)$ & 1.50 \\
\hline $\begin{array}{l}\text { Family Response } \\
0.001^{*}\end{array}$ & $36(75.8 \%)$ & $12(24.2 \%)$ & 24.00 \\
\hline $\begin{array}{l}\text { Type of Trials } \\
0.001^{*}\end{array}$ & $34(72.7 \%)$ & $14(27.3 \%)$ & 16.67 \\
\hline $\begin{array}{l}\text { Monetary Compensation } \\
0.004^{*}\end{array}$ & $17(35.4 \%)$ & $31(64.6 \%)$ & 8.17 \\
\hline
\end{tabular}

Table 1: Reasons for refusal to participate in Clinical trials amongst the forty-eight invited respondents.

\begin{tabular}{|c|c|c|c|}
\hline $\begin{array}{l}\text { Socio-demographic variables } \\
\text { P-value }\end{array}$ & Yes & No & $x^{2}$ \\
\hline \multicolumn{4}{|l|}{ Marital status } \\
\hline $\begin{array}{l}\text { Married }(n=124) \\
0.000^{*}\end{array}$ & $86(69.4 \%)$ & $38(30.6 \%)$ & 37.16 \\
\hline $\begin{array}{l}\text { Unmarried }(n=48) \\
0.001^{*}\end{array}$ & $15(30.6)$ & $33(69.4 \%)$ & 13.50 \\
\hline \multicolumn{4}{|l|}{ Educational level } \\
\hline $\begin{array}{l}\text { No formal Education } 11(6.3 \%) \\
0.001^{*}\end{array}$ & $10((91 \%)$ & $1(9 \%)$ & 14.73 \\
\hline $\begin{array}{l}\text { Primary } 62(37.7 \%) \\
0.000^{*}\end{array}$ & $54(87 \%)$ & $8(13 \%)$ & 68.26 \\
\hline $\begin{array}{l}\text { Secondary } 59(41.2 \%) \\
0.000^{*}\end{array}$ & $48(81.4 \%)$ & $11(18.6 \%)$ & 46.41 \\
\hline $\begin{array}{l}\text { Tertiary } 40(23.2 \%) \\
0.002^{*}\end{array}$ & $27(67.5 \%)$ & $13(32.5 \%)$ & 9.80 \\
\hline Total $172(100 \%)$ & $139(73.8 \%)$ & $33(26.2 \%)$ & \\
\hline
\end{tabular}

Table 2: Chi-square test of association between respondents' willingness to participate in clinical trials and the family constraints characterized by sociodemographic variables.

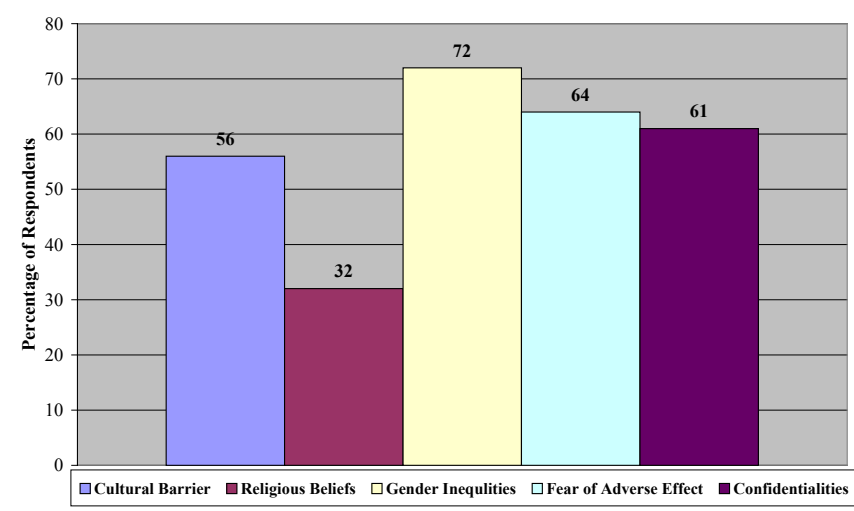

Figure 1: The challenges involved in enrolment and retention of African women in clinical trials as categorized by the 172 respondents. 
confidentialities for sensitive research (61\%). On what they considered motivating factors to ensure women participation in clinical trials, 112 $(65.1 \%)$ were of the view that education and awareness among women should be given adequate attention. One hundred and nine $(63.4 \%)$ cited lack of ability to make decision on the part of women in male dominated environment while $98(60 \%)$ were advocating for women empowerment to enable them contribute to issues concerning their health.

\section{Discussion}

In Nigeria, as it is often the case with other African countries, inability to be involved in decision-making even in matters pertaining to their health, may have made women under represented in clinical trials. Enrolment and retention of African women in clinical trials tend to be more difficult because of getting adequate informed consent from them, which is further complicated in women who lack formal education and may not understand the uncertainty that exists within the clinical trials procedures [6]. Consequently, out of the uncertainties in obtaining informed consent and the need to conduct research trials without hitches, some research designs, may from the on-set exclude women from participating. Also young mothers may be more hesitant to expose themselves to various forms of risks and therefore may not willingly give their consent [7]. This may explain why about (87.9\%) of unmarried respondents in this study were not bordered about getting consent from any family member to participate if invited to participate in any clinical trial, an indication that unmarried women may be at much liberty to decision-making than married women, cultural barrier notwithstanding. For the married women, there could be proxy consent because of the cultural norms that men can give consent or assent on behalf of their wives which apparently result to mediated autonomy. In such circumstances, the woman may at some points lose the zeal to continue with the research process. In this study we observed that most women were willing to participate in clinical trial but family factors such as domestic works, time pressure and inability to give consent without family members support were an impediment. It then means any clinical trials that will warrant many visits to the research site where multiple-transportation is involved will have fewer women willing to participate since it will be more tasking, time consuming and waste of money considering the socioeconomic condition of most African countries. Our study also shows that some of the respondents especially those with low level of education and limited knowledge of the type of clinical trials were concerned about the adverse effect they may encounter during the research process. Wessenaar and Barsdof [8] maintained that women's active informed participation in clinical trials and prevention efforts in general is important, but this participation becomes vital when women are most affected by a given disease. For example, they explained that women's distinct vulnerability to HIV means that HIV vaccine trials must include women, not only because vaccines have to be tested in high-risk groups, but more importantly because HIV vaccine candidates need to be tested for their safety, suitability and efficacy in women. Notwithstanding the need, it may be difficult to enroll and retain women in clinical trials that have substantial social risks such as HIV especially in an environment where ignorance and poverty are commonplace. This is because most of the women may be concerned about being tested positive in the course of the trials and their diagnostic test disclosed. For the women, any breach of confidentiality can lead to increased discrimination and harassment as well as been subjected to violence or abandonment by their male partners or to discrimination by their employers $[9,10]$. This may give an explanation to our findings. Out of the 48 women who were invited in the past to participate in a clinical trial only three (3.4\%) accepted to be enrolled and fully participated.

This study has shown that knowledge and education play important role in motivating women to participate in clinical trials in Africa while family attachments and cultural barrier are impediments to their participation. These represent serious challenges since the primary aim of research is to provide scientific evidence, which will lead to a change in health policy and standard of care. Therefore, clinical trials that do not include a sizeable number of women capable of generating data that could give reliable and generalizable information in comparison to male participants should not be encouraged. Government and law makers in collaboration with health policy makers should not only embark on awareness campaign but also introduce a system that will empower women to be able to make their own decisions on issues that concern their health. This will assist health policy makers to evaluate the allocation of resources for more research, prevention, treatment and provision of drugs, and support services taking cognizance of which group within the population are at lowest and highest risk.

\section{References}

1. Stoy DB (1994) Recruitment and Retention of Women in Clinical Studies: Theoretical Perspectives and Methodological Considerations. In: Mastoiann AC, Faden R, Federman DG (ed) Women and Health Research: Ethical and Legal Issues of Including Women in Clinical Studies. Washington: National Press 45-51.

2. Onuoha C (2007) Bioethics Across Borders: An African Perspective. Acta Universitatis Upsaliensis, Uppsala University.

3. Connell RW (1987) Gender and power: Society, the person and sexual politics. In: Palo Alto, Stanford University Press, Stanford, California.

4. Weijer C, Crouch RA (1999) Why should we include women and minorities in randomized controlled trials? J Clin Ethics 10: 100-106

5. Allen W (2000) Making progress in gender-specific medicine. Center Watch 7:1.

6. Emanuel EJ (2004) Ethical and regulatory aspects of clinical research. Johns Hopkins University Press, Baltimore, London 4: 171-175.

7. Kass N (1988) Gender and Research. In: Jeffrey Kahn, Anna Mastroianni, Jeremy Sagarman, Beyond Consent: Seeking Justice in Research. Oxford University Press, New York, USA

8. Wassenaar DR, Barsdorf NW (2007) The ethical involvement of women in HIV vaccine trials in Africa: discussion paper developed for the African AIDS Vaccine Programme. Women Health 1: 37-50.

9. Koblin BA, Holte S, Lenderking B, Heagerty P (2000) Readiness for HIV vaccine trials: changes in willingness and knowledge among high-risk populations in the HIV network for prevention trials. The HIV NET Vaccine Preparedness Study Protocol Team. J Acquir Immune Defic Syndr 24: 451-457.

10. Kapoor S (2004) Gender in AIDS vaccine trials: Addressing challenges in developing countries. New York: International AIDS Vaccine Initiative. . 